\title{
Genome sequence of the Lotus corniculatus microsymbiont Mesorhizobium loti strain R88B
}

\author{
Wayne Reeve ${ }^{1 *}$, John Sullivan², Clive Ronson², Rui Tian ${ }^{1}$, Lambert Bräu ${ }^{3}$, Karen Davenport ${ }^{4}$, Lynne Goodwin ${ }^{4}$, \\ Patrick Chain ${ }^{4}$, Tanja Woyke ${ }^{5}$, Elizabeth Lobos ${ }^{5}$, Marcel Huntemann ${ }^{5}$, Amrita Pati ${ }^{5}$, Konstantinos Mavromatis ${ }^{5}$, \\ Victor Markowitz ${ }^{6}$ Natalia Ivanova ${ }^{5}$ and Nikos Kyrpides ${ }^{5,7}$
}

\begin{abstract}
Mesorhizobium loti strain R88B was isolated in 1993 in the Rocklands range in Otago, New Zealand from a Lotus corniculatus root nodule. R88B is an aerobic, Gram-negative, non-spore-forming rod. This report reveals the genome of M. loti strain R88B contains a single scaffold of size 7,195,110 bp which encodes 6,950 protein-coding genes and 66 RNA-only encoding genes. This genome does not harbor any plasmids but contains the integrative and conjugative element ICEMISym ${ }^{\text {R7A }}$, also known as the R7A symbiosis island, acquired by horizontal gene transfer in the field environment from M. loti strain R7A. It also contains a mobilizable genetic element ICEMladh ${ }^{\text {R88B }}$, that encodes a likely adhesin gene which has integrated downstream of ICEMISYM ${ }^{R 7 A}$, and three acquired loci that together allow the utilization of the siderophore ferrichrome. This rhizobial genome is one of 100 sequenced as part of the DOE Joint Genome Institute 2010 Genomic Encyclopedia for Bacteria and Archaea-Root Nodule Bacteria (GEBA-RNB) project.
\end{abstract}

Keywords: Root-nodule bacteria, Nitrogen fixation, Symbiosis, Alphaproteobacteria

\section{Introduction}

Mesorhizobium loti strain R88B was first described in studies that culminated in the discovery of the M. loti strain R7A symbiosis island [1,2]. The research involved the characterization of genetic diversity within a population of mesorhizobia found beneath a stand of Lotus corniculatus located in the Rocklands range in Central Otago New Zealand. The site was established with a single inoculum strain ICMP3153 in an area lacking indigenous rhizobia capable of nodulating the plant. A group of genetically diverse mesorhizobial strains that included R88B were isolated from nodules seven years after the site was established. A field reisolate of ICMP3153 designated R7A was also isolated from the site and this strain has subsequently been used widely for molecular studies. Analysis of the diverse strains revealed that they all contained identical symbiotic DNA. Characterization of these strains led to the discovery of the 502-kb R7A symbiosis island, a mobile integrative and conjugative

\footnotetext{
* Correspondence: W.Reeve@murdoch.edu.au

${ }^{1}$ Centre for Rhizobium Studies, Murdoch University, Western Australia, Australia

Full list of author information is available at the end of the article
}

element that was subsequently renamed ICEMlSym ${ }^{\mathrm{R} 7 \mathrm{~A}}$ [3]. R88B contains no plasmids but ICEMlSym ${ }^{\mathrm{R} 7 \mathrm{~A}}$ is integrated at the phe-tRNA gene $[1,4]$. On the basis of DNA-DNA hybridization, multi-locus enzyme electrophoresis and $16 \mathrm{~S}$ rDNA sequence, R88B was shown to belong to the same genomic species as other symbiotic isolates and several nonsymbiotic isolates from the Rocklands site, but that strain R7A belonged to a different genomic species [5].

Examination of the genome sequence downstream of ICEMlSym ${ }^{\text {R7A }}$ in R88B revealed the presence of another ICE, ICEMladh ${ }^{\mathrm{R} 88 \mathrm{~B}}$, that encoded a large (4681 amino acids) adhesin-like protein with 34 VCBS repeats and two proteins that likely comprise a Type I secretion system for the adhesin. ICEMladh ${ }^{\mathrm{R} 88 \mathrm{~B}}$ also encoded an integrase, excisionase and traACD genes, indicating that the element is likely mobilizable by self-conjugative elements such as ICEMlSym ${ }^{\mathrm{R} 7 \mathrm{~A}}$. The discovery of ICEM$l \mathrm{adh}^{\mathrm{R} 88 \mathrm{~B}}$ showed that genomic islands can integrate in tandem at the phe-tRNA locus and also indicated that mesorhizobia may gain adaptive traits by acquisition of integrated genomic islands rather than plasmids [6].

M. loti strain R88B was also the focus of a study that catalogued variation in the ability to utilize the siderophore 
ferrichrome within the diverse set of $M$. loti strains [7]. Within R88B, the functional $f h u$ genes were found to be present in three co-ordinately regulated loci, each of which was independently acquired by the strain. The genes $f h u \mathrm{BD}$ that encode two of the three subunits of the ferrichrome $\mathrm{ABC}$ transporter were located downstream of ICEMladh ${ }^{\mathrm{R} 88 \mathrm{~B}}$ and were absent from the previously sequenced genome of M. loti strain MAFF303099. This suggests that these genes may have been part of another ICE that had integrated at the phe-tRNA locus. The finding that RirA binding sites were located upstream of the loci suggests that the genes are probably subject to regulation by the iron-responsive repressor RirA, a copy of which is present in the R88B genome. The mosaic nature of the R88B $f h u$ system, the variability observed in the ability of M. loti strains isolated from several sites in Central Otago, New Zealand to utilize ferrichrome, and the patchwork distribution of $f h u$ genes in these strains suggests that these loci evolved through cycles of gene acquisition and deletion, with the positive selection pressure of an iron-poor or siderophore-rich environment being offset by the negative pressure of the Fhu receptor being a target for phage [7].

Here we present a summary classification and a set of general features for M. loti strain R88B together with the description of the complete genome sequence and annotation.

\section{Organism information}

Mesorhizobium loti strain R88B is in the order Rhizobiales of the class Alphaproteobacteria. Cells are described as non-sporulating, Gram-negative (Figure 1 Left), nonencapsulated, rods. The rod-shaped form varies in size with dimensions of $0.25-0.5 \mu \mathrm{m}$ in width and $1-2 \mu \mathrm{m}$ in length (Figure 1 Left and Center). They are moderately fast growing, forming $1 \mathrm{~mm}$ diameter colonies within 6 days and have a mean generation time of approximately $8-12 \mathrm{~h}$ when grown in TY broth at $28^{\circ} \mathrm{C}$ [1]. Colonies on G/RDM agar [8] and half strength Lupin Agar ( $1 / 2 \mathrm{LA})$ [9] are white-opaque, slightly domed, mucoid with smooth margins (Figure 1 Right).

Strains of this organism are able to tolerate a $\mathrm{pH}$ range between 4 and 10. Carbon source utilization and fatty acid profiles of $M$. loti have been described previously [10-12]. Minimum Information about the Genome Sequence (MIGS) is provided in Table 1.

Figure 2 shows the phylogenetic neighborhood of $M$. loti strain R88B in a $16 \mathrm{~S}$ rRNA gene sequence based tree. This strain has $99.7 \%$ sequence identity (1364/ $1367 \mathrm{bp}$ ) at the $16 \mathrm{~S}$ rRNA sequence level to the sequenced M. australicum WSM2073 (GOLD ID: Gc02468) and 99.6\% 16S rRNA sequence $(1362 / 1367 \mathrm{bp})$ identity to the fully sequenced M. ciceri bv. biserrulae WSM1271 (GOLD ID: Gc01578).

\section{Symbiotaxonomy}

M. loti strain R88B was isolated from a stand of $L$. corniculatus bv. Goldie planted in 1986 at a field site which lacked naturalized rhizobia capable of nodulating the plant. The inoculum strain used was M. loti R7A (ICMP3153). The field site was an undeveloped tussock (Festuca novae-zealandiae and Chionochloa rigida) grassland located at an elevation of $885 \mathrm{~m}$ in Lammermoor, the Rocklands range, Otago, New Zealand. The soil was a dark brown silt loam with an acid $\mathrm{pH}(4.9)$ and a low (0.28\%) total nitrogen content. Prior to establishment of the site, R88B likely existed as a soil saprophyte that lacked symbiotic DNA. Subsequent transfer of ICEMlSym ${ }^{\text {R7A }}$ from the donor strain R7A converted R88B into a symbiont and, hence enabled R88B to nodulate $L$. corniculatus, leading to the isolation of R88B when field sampling was performed in 1993. R88B forms effective nodules on Lotus corniculatus, but it has not been tested on any other Lotus species to date.

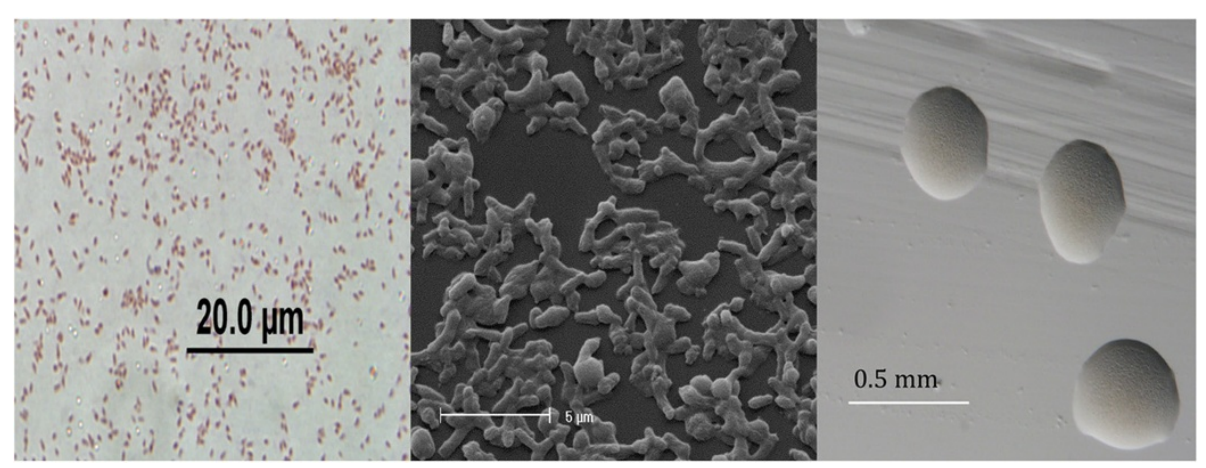

Figure 1 Images of Mesorhizobium loti strain R88B from a Gram stain (Left), using scanning electron microscopy (Center) and the appearance of colony morphology on $1 / 2$ LA (Right). 
Table 1 Classification and general features of Mesorhizobium loti strain R88B according to the MIGS recommendations $[13,14]$

\begin{tabular}{|c|c|c|c|}
\hline MIGS ID & Property & Term & Evidence code \\
\hline & Current classification & Domain Bacteria & TAS [14] \\
\hline & & Phylum Proteobacteria & TAS [15] \\
\hline & & Class Alphaproteobacteria & $\operatorname{TAS}[16,17]$ \\
\hline & & Order Rhizobiales & TAS $[17,18]$ \\
\hline & & Family Phyllobacteriaceae & TAS $[17,19]$ \\
\hline & & Genus Mesorhizobium & TAS [11] \\
\hline & & Species Mesorhizobium loti & TAS $[10,11]$ \\
\hline & & Strain R88B & TAS [1] \\
\hline & Gram stain & Negative & IDA \\
\hline & Cell shape & Rod & IDA \\
\hline & Motility & Motile & IDA \\
\hline & Sporulation & Non-sporulating & NAS \\
\hline & Temperature range & Mesophile & NAS \\
\hline & Optimum temperature & $28^{\circ} \mathrm{C}$ & NAS \\
\hline & Salinity & Unknown & NAS \\
\hline \multirow[t]{3}{*}{ MIGS-22 } & Oxygen requirement & Aerobic & TAS [10] \\
\hline & Carbon source & Various & TAS [11] \\
\hline & Energy source & Chemoorganotroph & TAS [11] \\
\hline MIGS-6 & Habitat & Soil, root nodule, host & TAS [10] \\
\hline MIGS-15 & Biotic relationship & Free living, Symbiotic & TAS [10] \\
\hline \multirow[t]{3}{*}{ MIGS-14 } & Pathogenicity & None & NAS \\
\hline & Biosafety level & 1 & TAS [20] \\
\hline & Isolation & Root nodule of Lotus corniculatus & TAS [1] \\
\hline MIGS-4 & Geographic location & Lammermoor, Otago NZ & TAS [1] \\
\hline MIGS-5 & Nodule collection date & 1993 & TAS [1] \\
\hline \multirow[t]{2}{*}{ MIGS-4.1 MIGS-4.2 } & Latitude & -45.53 & TAS [1] \\
\hline & Longitude & 169.9415 & TAS [1] \\
\hline MIGS-4.3 & Depth & $10 \mathrm{~cm}$ & IDA \\
\hline MIGS-4.4 & Altitude & 885 meters & IDA \\
\hline
\end{tabular}

Evidence codes - IDA: Inferred from Direct Assay; TAS: Traceable Author Statement (i.e., a direct report exists in the literature); NAS: Non-traceable Author Statement (i.e., not directly observed for the living, isolated sample, but based on a generally accepted property for the species, or anecdotal evidence). These evidence codes are from the Gene Ontology project [21].

\section{Genome Sequencing Information}

\section{Genome project history}

This organism was selected for sequencing on the basis of its environmental and agricultural relevance to issues in global carbon cycling, alternative energy production, and biogeochemical importance, and is part of the Community Sequencing Program at the U.S. Department of Energy, Joint Genome Institute (JGI), which is focused on projects of relevance to agency missions. The genome project is deposited in the Genomes OnLine Database [25] and an improved-high-quality-draft genome sequence in IMG. Sequencing, finishing and annotation were performed by the JGI. A summary of the project information is shown in Table 2.

\section{Growth conditions and DNA isolation}

M. loti strain R88B was grown to mid logarithmic phase in TY rich medium [26] on a gyratory shaker at $28^{\circ} \mathrm{C}$ at $250 \mathrm{rpm}$. DNA was isolated from $60 \mathrm{~mL}$ of cells using a CTAB (Cetyl trimethyl ammonium bromide) bacterial genomic DNA isolation method [27].

\section{Genome sequencing and assembly}

The draft genome of $M$. loti R88B was generated at the DOE JGI using Illumina [28] technology. For this genome, we constructed and sequenced an Illumina shortinsert paired-end library with an average insert size of 270 bp which generated 17,358,418 reads and an Illumina long-insert paired-end library with an average insert size 


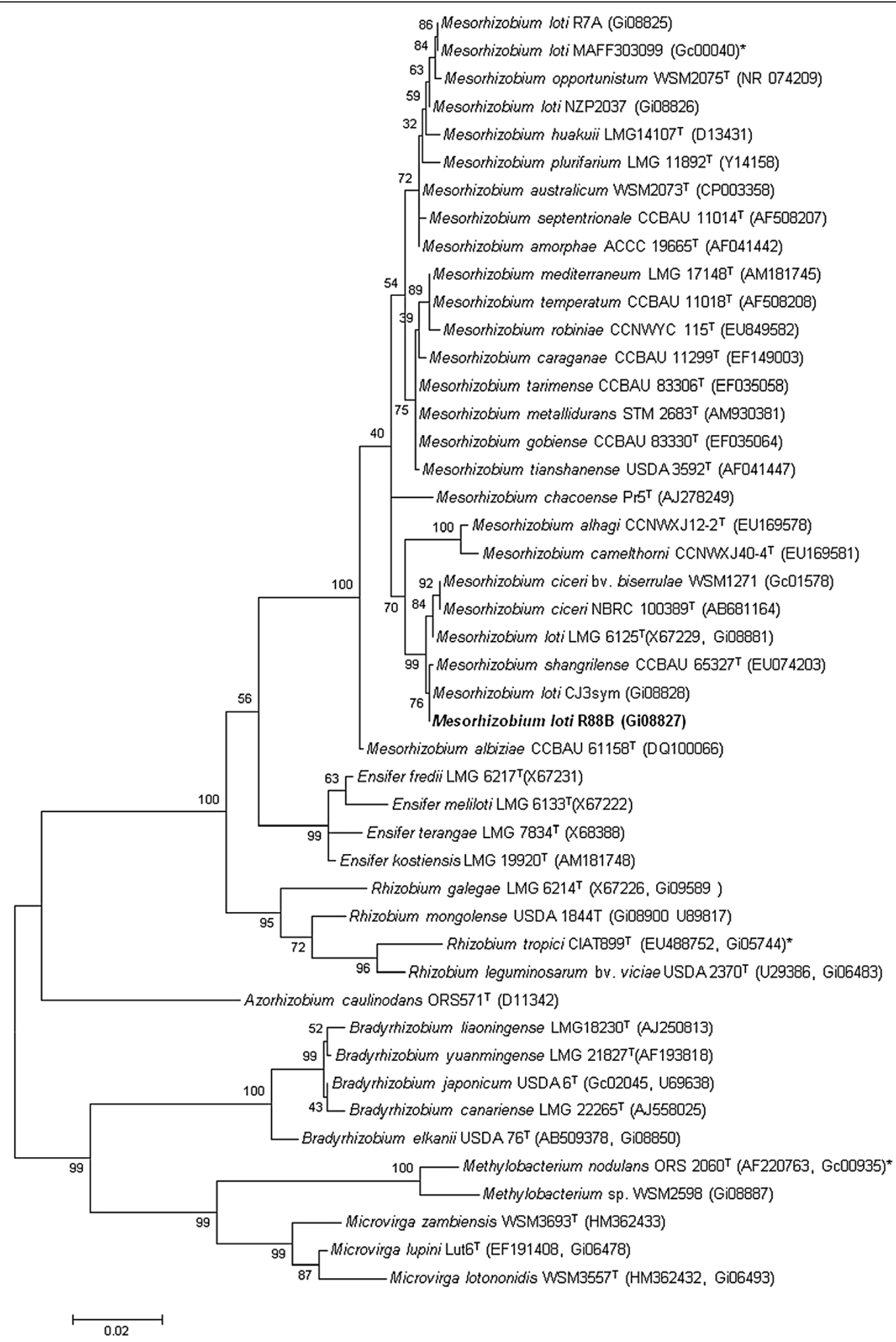

Figure 2 (See legend on next page.) 
(See figure on previous page.)

Figure 2 Phylogenetic tree showing the relationships of Mesorhizobium loti R88B with other root nodule bacteria based on aligned sequences of the $16 \mathrm{~S}$ rRNA gene (1,290 bp internal region). All sites were informative and there were no gap-containing sites. Phylogenetic analyses were performed using MEGA [22], version 5. The tree was built using the Maximum-Likelihood method with the General Time Reversible model [23]. Bootstrap analysis [24] with 500 replicates was performed to assess the support of the clusters. Type strains are indicated with a superscript T. Brackets after the strain name contain a DNA database accession number and/or a GOLD ID (beginning with the prefix G) for a sequencing project registered in GOLD [25]. Published genomes are indicated with an asterisk.

of 4,146+/-2,487 bp which generated $10,904,934$ reads totaling 4,240 Mbp of Illumina data (unpublished, Feng Chen). All general aspects of library construction and sequencing performed at the JGI can be found at the DOE Joint Genome Institute website [29].

The initial draft assembly contained 41 contigs in 9 scaffolds. The initial draft data were assembled with Allpaths, version 39750, and the consensus was computationally shredded into $10 \mathrm{Kbp}$ overlapping fake reads (shreds). The Illumina draft data were also assembled with Velvet, version 1.1.05 [30], and the consensus sequences were computationally shredded into $1.5 \mathrm{Kbp}$ overlapping fake reads (shreds). The Illumina draft data were assembled again with Velvet using the shreds from the first Velvet assembly to guide the next assembly. The consensus from the second VELVET assembly was shredded into $1.5 \mathrm{Kbp}$ overlapping fake reads. The fake reads from the Allpaths assembly and both Velvet assemblies and a subset of the Illumina CLIP paired-end reads were assembled using parallel phrap, version 4.24 (High Performance Software, LLC). Possible mis-assemblies were corrected with manual editing in Consed [31-33]. Gap closure was accomplished using repeat resolution software (Wei Gu, unpublished), and sequencing of bridging PCR fragments with Sanger technology.

Table 2 Genome sequencing project information for Mesorhizobium loti R88B

\begin{tabular}{lll}
\hline MIGS ID & Property & Term \\
\hline MIGS-31 & Finishing quality & Improved-high-quality-draft \\
MIGS-28 & Libraries used & $\begin{array}{l}\text { Illumina Standard (short PE) } \\
\text { and CLIP (long PE) libraries }\end{array}$ \\
MIGS-29 & Sequencing platforms & Illumina HiSeq2000 technology \\
MIGS-31.2 & Sequencing coverage & Illumina: 589x \\
MIGS-30 & Assemblers & Velvet version 1.1.05; Allpaths-LG \\
& & version r39750; phrap, version 4.24 \\
MIGS-32 & Gene calling method & Prodigal 1.4, GenePRIMP \\
& Genbank accession & JACE00000000 \\
& Genbank date of release & 12-OCT-2014 \\
& GOLD ID & Gi08827 \\
& NCBI project ID & 76961 \\
& Database: IMG & 2512875024 \\
& Project relevance & Symbiotic nitrogen fixation, \\
& & agriculture \\
\hline
\end{tabular}

For improved high quality draft, one round of manual/ wet lab finishing was completed. A total of 23 additional sequencing reactions were completed to close gaps and to raise the quality of the final sequence. The total ("estimated size" for unfinished) size of the genome is 7.2 Mbp and the final assembly is based on $4,240 \mathrm{Mbp}$ of Illumina draft data, which provided an average $589 \times$ coverage of the genome.

\section{Genome annotation}

Genes were identified using Prodigal [34] as part of the Oak Ridge National Laboratory genome annotation pipeline, followed by a round of manual curation using the JGI GenePrimp pipeline [35]. The predicted CDSs were translated and used to search the National Center for Biotechnology Information (NCBI) nonredundant database, UniProt, TIGRFam, Pfam, PRIAM, KEGG, COG, and InterPro databases. These data sources were combined to assert a product description for each predicted protein. Non-coding genes and miscellaneous features were predicted using tRNAscan-SE [36], RNAMMer [37], Rfam [38], TMHMM [39], and SignalP [40]. Additional gene prediction analyses and functional annotation were performed within the Integrated Microbial Genomes (IMG-ER) platform [41].

Table 3 Genome statistics for Mesorhizobium loti R88B

\begin{tabular}{lrr}
\hline Attribute & Value & \% of total \\
\hline Genome size (bp) & $7,195,110$ & 100.00 \\
DNA coding region (bp) & $6,308,527$ & 87.68 \\
DNA G + C content (bp) & $4,487,516$ & 62.37 \\
Number of scaffolds & 1 & \\
Number of contigs & 14 & \\
Total genes & 7,016 & 100.00 \\
RNA genes & 66 & 0.94 \\
rRNA operons & $2^{*}$ & \\
Protein-coding genes & 6,950 & 99.06 \\
Genes with function prediction & 5,552 & 79.13 \\
Genes assigned to COGs & 5,511 & 78.55 \\
Genes assigned Pfam domains & 5,800 & 82.67 \\
Genes with signal peptides & 651 & 9.28 \\
Genes coding transmembrane proteins & 1,669 & 23.79 \\
\hline *2 copies if 5S, 2 copies of 16S and 2 copies of 235 rRNA. &
\end{tabular}

* 2 copies if $5 S, 2$ copies of $16 \mathrm{~S}$ and 2 copies of $23 \mathrm{~S}$ rRNA. 
Table 4 Number of protein coding genes of Mesorhizobium loti R88B associated with the general COG functional categories

\begin{tabular}{|c|c|c|c|}
\hline Code & Value & $\%$ age & COG category \\
\hline J & 202 & 3.29 & Translation, ribosomal structure and biogenesis \\
\hline A & 1 & 0.02 & RNA processing and modification \\
\hline K & 572 & 9.32 & Transcription \\
\hline L & 181 & 2.95 & Replication, recombination and repair \\
\hline B & 5 & 0.08 & Chromatin structure and dynamics \\
\hline D & 33 & 0.54 & Cell cycle control, mitosis and meiosis \\
\hline Y & 0 & 0.00 & Nuclear structure \\
\hline V & 63 & 1.03 & Defense mechanisms \\
\hline $\mathrm{T}$ & 238 & 3.88 & Signal transduction mechanisms \\
\hline M & 330 & 5.38 & Cell wall/membrane biogenesis \\
\hline N & 43 & 0.70 & Cell motility \\
\hline Z & 1 & 0.02 & Cytoskeleton \\
\hline W & 1 & 0.02 & Extracellular structures \\
\hline U & 122 & 1.99 & Intracellular trafficking and secretion \\
\hline O & 188 & 3.06 & Posttranslational modification, protein turnover, chaperones \\
\hline C & 338 & 5.51 & Energy production conversion \\
\hline G & 567 & 9.24 & Carbohydrate transport and metabolism \\
\hline $\mathrm{E}$ & 751 & 12.24 & Amino acid transport metabolism \\
\hline $\mathrm{F}$ & 90 & 1.47 & Nucleotide transport and metabolism \\
\hline $\mathrm{H}$ & 230 & 3.75 & Coenzyme transport and metabolism \\
\hline । & 257 & 4.19 & Lipid transport and metabolism \\
\hline P & 272 & 4.43 & Inorganic ion transport and metabolism \\
\hline Q & 204 & 3.32 & Secondary metabolite biosynthesis, transport and catabolism \\
\hline $\mathrm{R}$ & 830 & 13.52 & General function prediction only \\
\hline$S$ & 619 & 10.08 & Function unknown \\
\hline- & 1,505 & 21.45 & Not in COGS \\
\hline
\end{tabular}
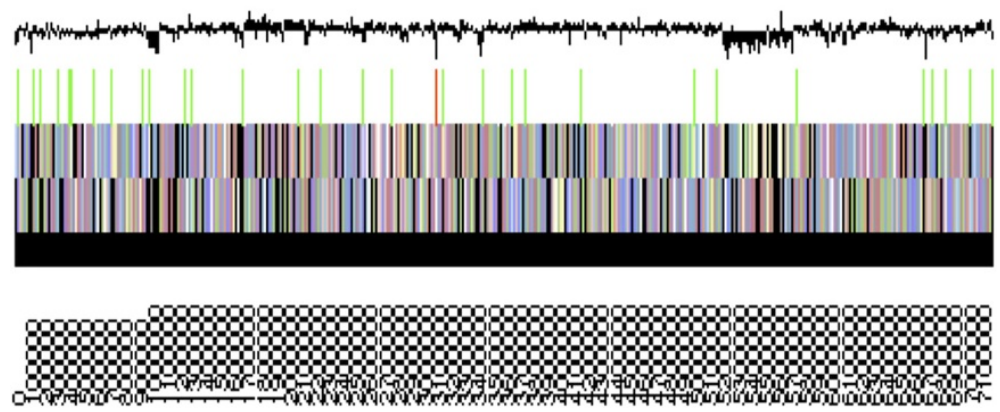

Figure 3 Graphical map of the single scaffold of Mesorhizobium loti R88B. From bottom to the top: Genes on forward strand (color by COG categories as denoted by the IMG platform), Genes on reverse strand (color by COG categories), RNA genes (tRNAs green, sRNAs red, other RNAs black), GC content, GC skew. 


\section{Genome properties}

The genome is 7,195,110 nucleotides with $62.37 \%$ GC content (Table 3) and is comprised of a single scaffold and no plasmids. From a total of 7,016 genes, 6,950 were protein encoding and 66 RNA-only encoding genes. Within the genome, 189 pseudogenes were also identified. The majority of genes (79.13\%) were assigned a putative function whilst the remaining genes were annotated as hypothetical. The distribution of genes into COGs functional categories is presented in Table 4 and Figure 3.

\section{Conclusion}

The $M$. loti strain R88B genome consists of a single chromosome of 7.2 Mb predicted to encode 7,016 genes. The sequencing was completed to the stage where a single scaffold comprising 14 contigs was obtained. $M$. loti strain R88B was isolated in New Zealand as a strain that gained symbiotic ability through receiving the $M$. loti strain R7A symbiosis island (now referred to as ICEMlSym ${ }^{\mathrm{R} A \mathrm{~A}}$ ) in the field environment $[1,2,3]$. On the basis of $16 \mathrm{~S}$ rRNA gene sequence similarity, strains able to nodulate Lotus species that have been examined to date appear to fall into two clusters (Figure 2). R88B is more closely related to M. loti strains LMG 6125 and CJ3Sym and M. ciceri strains NBRC 100389 and bv. biserrulae WSM1271, than to strains R7A, NZP2037 and MAFF303099 from which its 16SrRNA gene differs by over 20 nucleotides. It is clear that within the mesorhizobia the degree of $16 \mathrm{~S}$ rRNA gene sequence similarity observed between strains does not necessarily reflect host range. Strain R88B was also shown to contain at least two further regions of acquired DNA adjacent to ICEMlsym ${ }^{\mathrm{R} 7 \mathrm{~A}}$ that were likely present prior to arrival of ICEMlSym ${ }^{\mathrm{R} 7 \mathrm{~A}}$, indicating that tandem, sequential acquisition of elements that provide adaptive traits occurred at the phe-tRNA locus. One of these elements, ICEMlAdh ${ }^{\mathrm{R} 88 \mathrm{~B}}$, encoded an adhesin and tra genes required for mobilization in trans by another conjugative element. The other was a region containing $f h u$ genes involved in iron acquisition that was found to be one of three genomic regions required for utilization of the siderophore ferrichrome [6].

\section{Competing interests}

The authors declare that they have no competing interests.

\section{Authors' contributions}

JS and CR supplied the strain and background information for this project and helped WR write the paper, TR supplied DNA to JGI and performed all imaging, WR coordinated the project and all other authors were involved in either sequencing the genome and/or editing the paper. All authors read and approved the final manuscript.

\section{Acknowledgements}

This work was performed under the auspices of the US Department of Energy Office of Science, Biological and Environmental Research Program, and by the University of California, Lawrence Berkeley National Laboratory under contract No. DE-AC02-05CH11231, Lawrence Livermore National
Laboratory under Contract No. DE-AC52-07NA27344, and Los Alamos National Laboratory under contract No. DE-AC02-06NA25396.

\section{Author details}

${ }^{1}$ Centre for Rhizobium Studies, Murdoch University, Western Australia, Australia. ${ }^{2}$ Department of Microbiology and Immunology, University of Otago, Dunedin, New Zealand. ${ }^{3}$ School of Life and Environmental Sciences, Deakin University, Victoria, Australia. ${ }^{4}$ Los Alamos National Laboratory, Bioscience Division, Los Alamos, New Mexico, USA. ${ }^{5}$ DOE Joint Genome Institute, Walnut Creek, CA, USA. ${ }^{6}$ Biological Data Management and Technology Center, Lawrence Berkeley National Laboratory, Berkeley, CA, USA. ${ }^{7}$ Department of Biological Sciences, King Abdulaziz University, Jeddah, Saudi Arabia.

Received: 16 June 2014 Accepted: 16 June 2014

Published: 8 December 2014

\section{References}

1. Sullivan JT, Patrick HN, Lowther WL, Scott DB, Ronson CW. Nodulating strains of Rhizobium loti arise through chromosomal symbiotic gene transfer in the environment. Proc Natl Acad Sci USA. 1995; 92:8985-9. PubMed [http://dx.doi.org/10.1073/pnas.92.19.8985]

2. Sullivan JT, Ronson CW. Evolution of rhizobia by acquisition of a 500-kb symbiosis island that integrates into a phe-tRNA gene. Proc Natl Acad Sci USA. 1998; 95:5145-9. PubMed [http://dx.doi.org/10.1073/pnas.95.9.5145]

3. Ramsay JP, Sullivan JT, Stuart GS, Lamont IL, Ronson CW. Excision and transfer of the Mesorhizobium loti R7A symbiosis island requires an integrase IntS, a novel recombination directionality factor RdfS, and a putative relaxase RIxS. Mol Microbiol. 2006; 62:723-34. PubMed [http://dx.doi.org/10.1111/j.1365-2958.2006.05396.x]

4. Sullivan JT, Trzebiatowski JR, Cruickshank RW, Gouzy J, Brown SD, Elliot RM, Fleetwood DJ, McCallum NG, Rossbach U, Stuart GS, Weaver JE, Webby RJ, De Bruijn FJ, Ronson CW. Comparative sequence analysis of the symbiosis island of Mesorhizobium loti strain R7A. J Bacteriol. 2002; 184:3086-95. PubMed [http://dx.doi.org/10.1128/JB.184.11.3086-3095.2002]

5. Sullivan JT, Eardly BD, van Berkum P, Ronson CW. Four unnamed species of nonsymbiotic rhizobia isolated from the rhizosphere of Lotus corniculatus. Appl Environ Microbiol. 1996; 62:2818-25. PubMed

6. Ronson CW, Sullivan JT, Wijkstra GS, Carlton T, Muirhead K, Trzebiatowski JR, Gouzy J, Debruijn FJ. Genome diversity at the phe-tRNA locus in a field population of mesorhizobia. In: Finan TM, O'Brian MR, Layzell DB, Vessey JK, Newton WE, editors. Nitrogen Fixation: Global Perspectives. 2002: p. 66-70.

7. Carlton TM, Sullivan JT, Stuart GS, Hutt K, Lamont IL, Ronson CW. Ferrichrome utilization in a mesorhizobial population: microevolution of a three-locus system. Environ Microbiol. 2007; 9:2923-32. PubMed [http://dx.doi.org/10.1111/j.1462-2920.2007.01402.x]

8. Ronson CW, Nixon BT, Albright LM, Ausubel FM. Rhizobium meliloti ntrA $(r p o N)$ gene is required for diverse metabolic functions. J Bacteriol. 1987; 169:2424-31. PubMed

9. Howieson JG, Ewing MA, D'antuono MF. Selection for acid tolerance in Rhizobium meliloti. Plant Soil. 1988; 105:179-88 [http://dx.doi.org/10.1007/ BF02376781]

10. Jarvis BDW, Pankhurst CE, Patel JJ. Rhizobium loti, a new species of legume root nodule bacteria. Int J Syst Bacteriol. 1982; 32:378-80 [http://dx.doi.org/ 10.1099/00207713-32-3-378]

11. Jarvis BDW, Van Berkum P, Chen WX, Nour SM, Fernandez MP, Cleyet-Marel JC, Gillis M. Transfer of Rhizobium loti, Rhizobium huakuii, Rhizobium ciceri, Rhizobium mediterraneum, Rhizobium tianshanense to Mesorhizobium gen.nov. Int J Syst Evol Microbiol. 1997; 47:895-8.

12. Tighe SW, de Lajudie P, Dipietro K, Lindstrom K, Nick G, Jarvis BDW. Analysis of cellular fatty acids and phenotypic relationships of Agrobacterium, Bradyrhizobium, Mesorhizobium, Rhizobium and Sinorhizobium species using the Sherlock Microbial Identification System. Int J Syst Evol Microbiol. 2000; 50:787-801. PubMed [http://dx.doi.org/10.1099/0020771350-2-787]

13. Field D, Garrity G, Gray T, Morrison N, Selengut J, Sterk P, Tatusova T, Thomson N, Allen M, Angiuoli S, Ashburner M, Axelrod N, Baldauf S, Ballard S, Boore J, Cochrane G, Cole J, Dawyndt P, Vos P, dePamphilis C, Edwards R, Faruque N, Feldman R, Gilbert J, Gilna P, Glöckner F, Goldstein P, Guralnick R, Haft D, Hancock D, et al. Towards a richer description of our complete collection of genomes and metagenomes "Minimum Information about a Genome 
Sequence" (MIGS) specification. Nat Biotechnol. 2008; 26:541-7. PubMed [http://dx.doi.org/10.1038/nbt1360]

14. Woese CR, Kandler O, Wheelis ML. Towards a natural system of organisms: proposal for the domains Archaea, Bacteria, and Eucarya. Proc Natl Acad Sci USA. 1990; 87:4576-9. PubMed [http://dx.doi.org/10.1073/ pnas.87.12.4576]

15. Garrity GM, Bell JA, Lilburn T. Phylum XIV. Proteobacteria phyl. nov. In: Garrity GM, Brenner DJ, Krieg NR, Staley JT, editors. Bergey's Manual of Systematic Bacteriology, 2nd edition, Volume 2, Part B. New York: Springer; 2005: p. 1.

16. Garrity GM, Bell JA, Lilburn T. Class I. Alphaproteobacteria class. In: Garrity GM, Brenner DJ, Kreig NR, Staley JT, editors. Bergey's Manual of Systematic Bacteriology. 2nd ed. New York: Springer - Verlag; 2005.

17. Validation List No. 107. List of new names and new combinations previously effectively, but not validly, published. Int J Syst Evol Microbiol. 2006; 56:1-6. PubMed [http://dx.doi.org/10.1099/ijs.0.64188-0]

18. Kuykendall LD. Order VI. Rhizobiales ord. nov. In: Garrity GM, Brenner DJ, Kreig NR, Staley JT, editors. Bergey's Manual of Systematic Bacteriology. 2nd ed. New York: Springer - Verlag; 2005: p. 324

19. Mergaert J, Swings J. Family IV. Phyllobacteriaceae. In: Garrity GM, Brenner DJ, Kreig NR, Staley JT, editors. Bergy's Manual of Systematic Bacteriology. 2nd ed. New York: Springer - Verlag; 2005: p. 393.

20. Biological Agents. Technical rules for biological agents. TRBA. 466. [http://www.baua.de]

21. Ashburner M, Ball CA, Blake JA, Botstein D, Butler H, Cherry JM, Davis AP, Dolinski K, Dwight SS, Eppig JT, Harris MA, Hill DP, Issel-Tarver L, Kasarskis A, Lewis S, Matese JC, Richardson JE, Ringwald M, Rubin GM, Sherlock G. Gene ontology: tool for the unification of biology. The Gene Ontology Consortium. Nat Genet. 2000; 25:25-9. PubMed [http://dx.doi.org/10.1038/ 75556]

22. Tamura K, Peterson D, Peterson N, Stecher G, Nei M, Kumar S. MEGA5: molecular evolutionary genetics analysis using maximum likelihood, evolutionary distance, and maximum parsimony methods. Mol Biol Evol. 2011, 28:2731-9. PubMed [http://dx.doi.org/10.1093/molbev/msr121]

23. Nei M, Kumar S. Molecular Evolution and Phylogenetics. New York: Oxford University Press; 2000.

24. Felsenstein J. Confidence limits on phylogenies: an approach using the bootstrap. Evolution. 1985; 39:783-91 [http://dx.doi.org/10.2307/2408678]

25. Liolios K, Mavromatis K, Tavernarakis N, Kyrpides NC. The Genomes On Line Database (GOLD) in 2007: status of genomic and metagenomic projects and their associated metadata. Nucleic Acids Res. 2008; 36:D475-9. PubMed [http://dx.doi.org/10.1093/nar/gkm884]

26. Beringer JE. R factor transfer in Rhizobium leguminosarum. J Gen Microbiol. 1974; 84:188-98. PubMed [http://dx.doi.org/10.1099/00221287-84-1-188]

27. DOE JGI user homepage. [http://my.jgi.doe.gov/general/index.html]

28. Bennett S. Solexa Ltd. Pharmacogenomics. 2004; 5:433-8. PubMed [http://dx.doi.org/10.1517/14622416.5.4.433]

29. DOE Joint Genome Institute. [http://www.jgi.doe.gov/]

30. Zerbino DR. Using the Velvet de novo assembler for short-read sequencing technologies. Curr Protoc Bioinformatics. 2010; Chapter 11:Unit 115.

31. Ewing B, Green P. Base-calling of automated sequencer traces using phred. II. Error probabilities. Genome Res. 1998; 8:186-94. PubMed [http://dx.doi.org/10.1101/gr.8.3.175]

32. Ewing B, Hillier L, Wendl MC, Green P. Base-calling of automated sequencer traces using phred. I. Accuracy assessment. Genome Res. 1998; 8:175-85. PubMed [http://dx.doi.org/10.1101/gr.8.3.175]

33. Gordon D, Abajian C, Green P. Consed: a graphical tool for sequence finishing. Genome Res. 1998; 8:195-202. PubMed [http://dx.doi.org/ 10.1101/gr.8.3.195]

34. Hyatt D, Chen GL, Locascio PF, Land ML, Larimer FW, Hauser L. Prodigal: prokaryotic gene recognition and translation initiation site identification. BMC Bioinformatics. 2010; 11:119. PubMed [http://dx.doi.org/10.1186/ 1471-2105-11-119]

35. Pati A, Ivanova NN, Mikhailova N, Ovchinnikova G, Hooper SD, Lykidis A, Kyrpides NC. GenePRIMP: a gene prediction improvement pipeline for prokaryotic genomes. Nat Methods. 2010; 7:455-7. PubMed [http://dx.doi. org/10.1038/nmeth.1457]

36. Lowe TM, Eddy SR. tRNAscan-SE: a program for improved detection of transfer RNA genes in genomic sequence. Nucleic Acids Res. 1997; 25:955-64. PubMed [http://dx.doi.org/10.1093/nar/25.5.0955]

37. Lagesen K, Hallin P, Rodland EA, Staerfeldt HH, Rognes T, Ussery DW RNAmmer: consistent and rapid annotation of ribosomal RNA genes.
Nucleic Acids Res. 2007; 35:3100-8. PubMed [http://dx.doi.org/10.1093/ nar/gkm160]

38. Griffiths-Jones S, Bateman A, Marshall M, Khanna A, Eddy SR. Rfam: an RNA family database. Nucleic Acids Res. 2003; 31:439-41. PubMed [http://dx.doi. org/10.1093/nar/gkg006]

39. Krogh A, Larsson B, von Heijne G, Sonnhammer EL. Predicting transmembrane protein topology with a hidden Markov model: application to complete genomes. J Mol Biol. 2001; 305:567-80. PubMed [http://dx.doi.org/10.1006/ jmbi.2000.4315]

40. Bendtsen JD, Nielsen H, von Heijne G, Brunak S. Improved prediction of signal peptides: SignalP 3.0. J Mol Biol. 2004; 340:783-95. PubMed [http://dx.doi.org/10.1016/j.jmb.2004.05.028]

41. Markowitz VM, Mavromatis K, Ivanova NN, Chen IM, Chu K, Kyrpides NC. IMG ER: a system for microbial genome annotation expert review and curation. Bioinformatics. 2009; 25:2271-8. PubMed [http://dx.doi.org/ 10.1093/bioinformatics/btp393]

doi:10.1186/1944-3277-9-3

Cite this article as: Reeve et al: Genome sequence of the Lotus corniculatus microsymbiont Mesorhizobium loti strain R88B. Standards in Genomic Sciences 2014 9:3.

\section{Submit your next manuscript to BioMed Central and take full advantage of:}

- Convenient online submission

- Thorough peer review

- No space constraints or color figure charges

- Immediate publication on acceptance

- Inclusion in PubMed, CAS, Scopus and Google Scholar

- Research which is freely available for redistribution

Submit your manuscript at www.biomedcentral.com/submit
C BioMed Central 